\title{
Practical value of the new system for Maspin assessment, in colorectal cancer
}

\author{
S. GURZU ${ }^{1, *}$, Z. SZENTIRMAY², D. POPA ${ }^{3}$, I. JUNG ${ }^{1}$ \\ ${ }^{1}$ Department of Pathology, University of Medicine and Pharmacy, Targu-Mures, Romania; ${ }^{2}$ Department of Pathology and Molecular Biology, \\ National Institute of Oncology, Budapest, Hungary
}

*Correspondence: simonagurzu@yahoo.com

Received November 11, 2012 / Accepted January 7, 2013

\begin{abstract}
Maspin is a serine protease which belongs to the serpin family and seems to play an important role in inhibiting angiogenesis and tumor proliferation. The significance of its expression in colorectal cancer (CRC) has not been elucidated so far. In our study, we tried to identify, based on Maspin expression, four groups of CRC, with possible prognostic impact. In $121 \mathrm{CRC}$, we analyzed the Maspin expression in correlation with the clinico-pathological features, microsatellite status and other markers such as p53, bax, bcl-2, VEGF (Vascular Endothelial Growth Factor) and CD31. Based on the percentage and intensity of Maspin expression in the tumor cells, the cases were grouped in four classes: negative, with cytoplasmic predominance, nuclear predominated, and cases with mixed (cytoplasmic-nuclear) expression. $9 \%$ of the cases were negative, $44 \%$ presented cytoplasmic predominance, the nuclear predominance was revealed in $24 \%$ of the cases, and the other $23 \%$ of CRC having a mixed Maspin positivity. The cytoplasmic predominance was correlated with a better prognosis, p53 negativity, bax positivity, and lack of tumor budding. Forty percent of microsatellite instable (MSI) cases presented mixed expression, this pattern being also related to a lower angiogenesis. Nuclear predominance was associated with p53 positivity, the lowest survival rate and intense VEGF expression. In conclusion, CRC with cytoplasmic predominance and mixed Maspin expression seems to present better prognosis whereas nuclear predominance is connected with high aggressivity.
\end{abstract}

Key words: colorectal cancer, Maspin, bax, CD31

Maspin (Serpin $\mathrm{B}_{5}$ ) is a serine protease which belongs to the serpin (serine protease inhibitor) family, the same as plasminogen activator inhibitors (PAI 1 and 2 ) and $\alpha-1$ antitrypsin. It seems that it plays an important role in inhibiting tumor proliferation by increasing cell adhesion and motility [1]. It is also supposed to have antiangiogenic properties [1]. Maspin was first isolated from normal mammary myoepithelial cells in 1994 [2]. Its immunohistochemical expression was observed in normal epithelium of the breast, prostate, thymus, small intestine, colon, testis, placenta and stomach, predominantly in the cytoplasm [3].

Research results regarding Maspin activity are very controversial and the molecular mechanism responsible for its properties still remains unelucidated [4].

It is usually admitted that Maspin is a tumor suppressor gene which can be silenced by epigenetic alteration, in mammary cancers, but can also inhibit tumor progression in prostate and head and neck cancers which display high aggressivity in loss expressed-cases [5]. Another property which was attributed to the Maspin gene was the proapoptotic effect mediated by the bcl-2/bax family and caspase system in pancreatic, breast, skin and corneal tumors [6]. At the same time, other studies revealed that Maspin can also be an oncogene, its up-regulation being associated with unfavorable prognosis in cancers of the pancreas, skin, ovary, thyroid, stomach, lung, bladder, and even breast cancer $[7,8,9,10,11]$.

The Maspin antiangiogenic activity either exerts toward the basic fibroblast growth factor and the VEGF (Vascular Endothelial Growth Factor), limiting vessel mitogenesis and tube formation, or it leads to the decrease of vascular density, blocking endothelial cell migration [4]. The paracrine-mediated degradation of the extracellular matrix membrane was also suggested [12]. 
One of the most controversial aspects of Maspin immunohistochemical expression refers to its scoring assessment. Diverse results regarding the significance of Maspin expression are reported due to the independent quantification of cytoplasmic or nuclear expression and also to the use of the tissue microarray technique (TMA).

Fewer than 30 papers were recently published regarding Maspin expression in colorectal cancer (CRC). In our study, we analyzed Maspin expression and its correlation with other immunohistochemical markers, which revealed tumor aggressivity (p53), proapoptotic (bax) and antiapoptotic activity (bcl-2), angiogenic immunophenotype (VEGF-A), and microvessel density (CD31). The relationship between Maspin expression and microsatellite status was also investigated. Due to the controversial results regarding the significance of nuclear or cytoplasmic expression, we evaluated both nuclear and cytoplasmic immunoreactivity and tried to identify four groups of CRC, with possible prognostic and predictive value.

\section{Materials and methods}

In 121 cases of colorectal adenocarcinomas (41 from proximal colon, 24 from distal colon, and 56 from rectum), we performed immunohistochemical (IHC) reactions with the following antibodies: Maspin, p53, bax, bcl-2, CD31 and VEGF-A.

Processing of the cases was approved by the Ethical Committee of University of Medicine and Pharmacy of TarguMures, Romania. Written informed consent was obtained from each patient prior to beginning any research. The patients' follow-up was 36 months.

Quantification of tumor budding. Tumor budding quantification was performed at $\mathrm{x} 20$ objective lens by two pathologists. The used statistical method for interobserver variability is described below. An isolated single tumor cell and a cluster composed of fewer than five cancer cells, in the invasion front, were considered as 'budding' foci, according to the criteria of Ueno et al. [13]. We did not quantify the intensity of tumor budding.
Immunohistochemical stains. UltraVision system by D-Line, LabVision (Fremont, CA, USA), was used for immunohistochemical reactions in formalin-fixed, paraffinembedded tissues. The sections were deparaffinized, incubated at $100^{\circ} \mathrm{C}$, and washed with distilled water previous to hydrogen peroxide incubation. Subsequently, they were washed in Trisbuffered-saline (TBS) and incubated with primary antibodies for 60 minutes. For the secondary developing reagents the streptavidin peroxidase solution and biotinylated goat antipolyvalent solution (D-Line, LabVision) were used. The slides were developed using diaminobenzidine (DAB; Dako) and counterstained with Mayer's hematoxylin.

Methods for antigen retrieval, the dilution and clones of the antibodies and also the positive controls used to control the quality of the immunostains can be found in Table 1. For negative controls, incubation was performed with omission of the specific antibodies.

To prevent non-specific staining, endogenous biotin and enzyme interference we used for each case negative and positive controls and also an external quality control was performed. The pre-immunohistochemistry steps were also controled, including the formalin neutralization and fixation and paraffin-embedded processes. The non-specific negative reagent control in place of primary antibody was used to evaluate the non-specific staining, according to the manufacturer's instructions.

Molecular analysis. Molecular examinations were performed to determine the microsatellite status. DNA was manually extracted from formalin-fixed, paraffin-embedded tissues. From tumor tissue and normal mucosa manual $5-\mu \mathrm{m}$ micro-dissections were performed. DNA isolation was done using the High Pure PCR Template Preparation Kit (Roche $\mathrm{GmbH}$, Mannheim, Germany). DNA quality was checked by electrophoresis. DNA concentration was determined using the Nanodrop machine. In each case specifically dilutions were prepared to have a 50-100 ng template DNA.

To determine the microsatellite status we used real-time Light Cycler plate PCR 480 (Roche GmbH, Mannheim, Ger-

Table 1. The main characteristics of the antibodies used for immunostains

\begin{tabular}{|c|c|c|c|c|}
\hline Antibody (company) & Clone & Dilution & Antigen retrieval & Positive control \\
\hline $\begin{array}{l}\text { Maspin } \\
\text { (Novocastra, Newcastle-upon-Tyne, UK) }\end{array}$ & EAW24 & $1: 50$ & $\begin{array}{l}\text { Incubation with a } 10 \mathrm{mM} \text { sodium citrate } \\
\text { buffer (pH 6.0) for } 30 \text { minutes at } 100^{\circ} \mathrm{C}\end{array}$ & $\begin{array}{l}\text { - external - prostate and myoepithelial cells (breast) } \\
\text { - internal - NS }\end{array}$ \\
\hline $\begin{array}{l}\text { p53 } \\
\text { (LabVision, Fremont, CA, USA) }\end{array}$ & DO-7 & $1: 50$ & $\begin{array}{l}\text { Incubation with a } 10 \mathrm{mM} \text { sodium citrate } \\
\text { buffer }(\mathrm{pH} 6.0) \text { for } 30 \text { minutes at } 100^{\circ} \mathrm{C}\end{array}$ & $\begin{array}{l}\text { - external - normal colon mucosa - basal cells } \\
\text { - internal - normal colon mucosa - basal cells }\end{array}$ \\
\hline $\begin{array}{l}\text { Bcl-2 } \\
\text { (LabVision, Fremont, CA, USA) }\end{array}$ & 100/D5 & $1: 50$ & $\begin{array}{l}\text { Incubation with a } 10 \mathrm{mM} \text { sodium citrate } \\
\text { buffer ( } \mathrm{pH} \text { 6.0) for } 30 \text { minutes at } 100^{\circ} \mathrm{C}\end{array}$ & $\begin{array}{l}\text { - external - tonsil and lymph node } \\
\text { - internal - lymphocytes }\end{array}$ \\
\hline $\begin{array}{l}\text { Bax } \\
\text { (LabVision, Fremont, CA, USA) }\end{array}$ & $2 \mathrm{D} 2$ & $1: 50$ & $\begin{array}{l}\text { Incubation with a } 10 \mathrm{mM} \text { sodium citrate } \\
\text { buffer ( } \mathrm{pH} 6.0 \text { ) for } 30 \text { minutes at } 100^{\circ} \mathrm{C}\end{array}$ & $\begin{array}{l}\text { - external - Hodgkin's lymphoma } \\
\text { - internal - NS }\end{array}$ \\
\hline $\begin{array}{l}\text { CD31 } \\
\text { (Dako, Glostrup, Denmark) }\end{array}$ & JC70A & $1: 50$ & $\begin{array}{l}\text { Incubation with a } 10 \mathrm{mM} \text { sodium citrate } \\
\text { buffer ( } \mathrm{pH} 6.0 \text { ) for } 30 \text { minutes at } 100^{\circ} \mathrm{C}\end{array}$ & $\begin{array}{l}\text { - external - normal vessels - endothelial cells } \\
\text { - internal - normal mature vessels }\end{array}$ \\
\hline $\begin{array}{l}\text { VEGF-A } \\
\text { (LabVision, Fremont, CA, USA) }\end{array}$ & VG1 & $1: 25$ & $\begin{array}{l}\text { Incubation with Tris-EDTA solution }(\mathrm{pH} \\
10.0) \text { for } 30 \text { minutes at } 100^{\circ} \mathrm{C}\end{array}$ & $\begin{array}{l}\text { - external - renal tubes } \\
\text { - internal - normal mature vessels - endothelial cells }\end{array}$ \\
\hline
\end{tabular}


many), the method of high-resolution melting peak analysis, SYBR Green detection format.

BAT25 and BAT26 mononucleotides were used. Specifically primers, previously published [14], were used for BAT25 (forward 5' - TCGCCTCCAAGAATGTAAGT - 3' and reverse $5^{\prime}$ - TCTGCATTTTAACTATGGCTC - $3^{\prime}$ ) and BAT26 (forward 5 ' - TGACTACTTTTGACTTCAGCC - 3' and reverse $5^{\prime}$ - AACCATTCAACATTTTTAACCC-3').

For each sample, the Master Mix of BAT25 and BAT26 was composed by: Light Cycler DNA Master Hybridization ProbesMix Roche Molecular Biochemicals $(10 \mu \mathrm{l}), \mathrm{MgCl}_{2}-3.5 \mathrm{mM}$ $(2.8 \mu \mathrm{l})$, Primers- $10 \mu \mathrm{m}$ each $(0.4+0.4 \mu \mathrm{l}), \mathrm{H}_{2} \mathrm{O}$-PCR grade $(1.4 \mu \mathrm{l})$. The $15 \mu \mathrm{l}$ MasterMix of each BAT assay was combined with $5 \mu$ l template DNA in plate capillaries, which were centrifuged before introduction in the LightCycler rotor.

For the LightCycler amplification the following protocol was used: DNA preincubation, for activation of FastStart Taq DNA Polymerase and denaturation of template DNA (1 cycle, $95^{\circ} \mathrm{C}, 10$ minutes), followed by amplification of target DNA $\left(55\right.$ cycles $-94^{\circ} \mathrm{C}, 30 \mathrm{~s}$ followed by $60^{\circ} \mathrm{C}, 15 \mathrm{~s}$ and $72^{\circ} \mathrm{C}, 10 \mathrm{~s}$ ), melting of the amplicon with high resolution data acqusition ( 1 cycle, $95^{\circ} \mathrm{C}, 60 \mathrm{~s}$ followed by $40^{\circ} \mathrm{C}, 60 \mathrm{~s}$, followed by $55^{\circ} \mathrm{C}$, $1 \mathrm{~s}$ and $95^{\circ} \mathrm{C}$, continous), and cooling the rotor and thermal chamber $\left(1\right.$ cycle, $\left.40^{\circ} \mathrm{C}, 30 \mathrm{~s}\right)$.

For each cycle, non-template control (distilled water) and also controls for MSS (microsatellite stable tumor) and MSI (microsatellite instability) cases were used, with samples from our lab, previously proved to be MSS or MSI cases.

PCR products and the primers' length were analyzed by using the LightCycler ${ }^{\circ} 480$ software (Roche GmbH, Mannheim, Germany). For BAT26 the average melting peak value was $51.2^{\circ} \mathrm{C}$ for MSS respectively $45.5^{\circ} \mathrm{C}$ for MSI. For BAT25 the average values were $45.1^{\circ} \mathrm{C}$ for MSS respectively $42.4^{\circ} \mathrm{C}$ for MSI.

Based on the Dietmaier's classical definition of the microsatellite instability "a tumor with a least two unstable markers is defined as MSI-H (high frequency microsatellite instability)" [15]. Taking into account that the mononucleotides BAT25 and BAT26 are the most sensitive markers for colorectal carcinomas [14], we defined a tumor to be MSI-H if both BAT25 and BAT26 showed instability. The cases which presented MSI status with only one of the mononucleotides were not included in this study.

Immunohistochemical staining scoring. Maspin immunoreactivity was evaluated in both nuclei and cytoplasm. The staining intensity and percentage of immunoreactive cells were evaluated in each sample, in superficial tumor areas, and in the invasion front, respectively in the tumor budding areas, resulting in an average of the highly expressed areas (Table 2, Fig. 1). The cytoplasmic and nuclear assessment was performed at $\times 20$ objective lens, with Nikon 800E optical microscope, with digital photo camera. To have correct results, 6 microscopic fields were analyzed for each sample: 3 fields in the superficial areas and other three in the deepest areas, which were considered to be the invasion front. Based on the criteria presented in Table 2 , respectively the percentage of positive nuclei and number and intensity of tumor cells with cytoplasmic positivity, the cases were grouped in four classes: negative cases, cases with cytoplasmic predominance, cases with nuclear expression and carcinomas with mixed expression (cytoplasm and nuclei). The used cut-off value of positivity was $10 \%$ for nuclear expression and also $10 \%$ for the cytoplasmic one.

In all cases the subcellular Maspin expression was also evaluated in peritumoral areas, respectively in normal mucosa and the dysplastic glands.

Two pathologists quantified independently Maspin expression without knowledge of clinical outcome. To increase the objectivity of results, we performed digital photo from each case: 6 photo for each case. In cases with significant different results among the two pathologists, these pictures were evaluated and a final result was established. The used statistical method for interobserver variability, for tumor budding quantification and Maspin assessement, is described below.

The staining results for the other antibodies (p53, bcl-2, bax, VEGF) were interpreted by a well qualified pathologist, without knowing other clinico-pathological characteristics of the analyzed cases.

A positive reaction for $\mathrm{p} 53$ protein was defined as nuclear staining in $>10 \%$ of the tumor cell nuclei. The cut-off value for cytoplasmic positivity of bax, bcl-2 and VEGF-A was $10 \%$ of positive cells.

The microvessel density (MVD) was counted with CD31 using the NIH's ImageJ software, an image analysis system. The ulcerated and inflammatory areas were eliminated. The MVD was recorded by counting the CD31-positive vessels in the highly vascularized ("hot-spot") areas, at 200x high-power fields. We batch-measured the percentage of positive endothelial area versus total area of the microscopic field.

Statistical analysis. Microsoft Excel table was created containing all the clinical, morphological, and immunohistochemical data of tumors. Frequency distributions were

Table 2. Immunohistochemical criteria used for the quantification of Maspin expression

\begin{tabular}{lcc}
\hline Maspin immunoreactivity in the tumor cells & Nuclei & Interpretation \\
\hline Cytoplasm & $<10 \%$ & negative \\
\hline$<10 \%$ & $<10 \%$ & cytoplasmic predominance \\
intense expression $\geq 10 \%$ but $<25 \%$ & $\geq 10 \%$ but $<25 \%$ & nuclear predominance \\
negative or slight expression $<10 \%$ & $\geq 25 \%$ & mixed expression \\
intense expression $\geq 25 \%$ & &
\end{tabular}




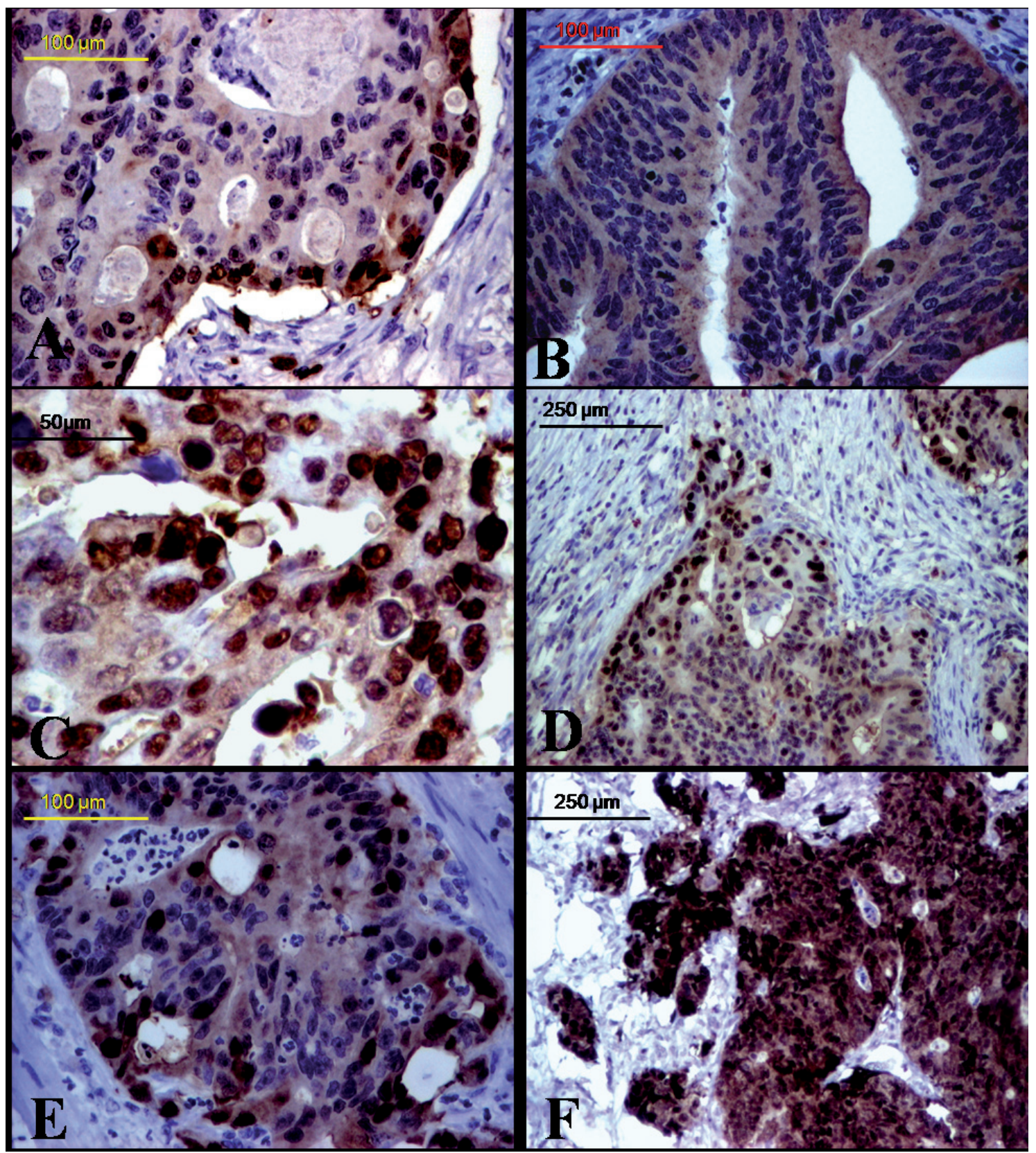

Fig. 1. Maspin quantification based on the cytoplasmic and nuclear expression. A. In negative cases, the nuclei became positive in the invasion front; B. Cytoplasmic predominance; C-D. Nuclear predominance, with increased intensity in the invasion front; E-F. Mixed expression, with increased intensity in the invasion front.

calculated using Excel functions. All the further statistical analyses were performed using the Graph Pad statistical software. The Kaplan-Meier curves and Cox proportional hazard regression were performed using MedCalc software.

In case of Maspin scorring and quantification of tumor budding, the interobserver variability was calculated by Cohen's kappa-type statistic test [16], with the following interpretation of $\kappa$ values: $0.20-0.40$ - fair-, 0.41-0.60
- moderate - respectively almost perfect - agreement in case of values $>0.60$. In case of disagreement between the two independent observers a consensus score was established reevaluating the cases.

Correlation between Maspin expression, clinicopathological, immunohistochemical and molecular variables were performed using the two-sided Fisher's exact test and Spearman's rank correlation test, respectively. The patients' age was 
expressed in mean \pm standard deviation and was analyzed with Pearson's or student's t-test. A p-value of less than 0.05 with $95 \%$ confidence interval was considered statistically significant. All tests were two-tailed, with a $95 \%$ confidence interval. Cases with missing some of evaluated values were excluded from this study.

Univariate survival analyses of the overall survival (OS) was determined using the Kaplan-Meier method and the two-sided Log Rank testing with the time of surgery as the onset.

For the multiple variable analyses, we used Cox proportional hazard regression. Each clinical, pathological and immunohistochemical variables were analyzed to determine which of them had an independent prognostic value.

\section{Results}

Univariate analyses. Maspin expression and clinico-pathological features. As we already mentioned, two pathologists quantified independently Maspin expression without knowledge of clinical outcome. All cases with divergent results were reassessed. Concordance of the results was $92 \%$ and the mean $\kappa$ value was 0.65 and 0.71 for interpretation in the superficial tumoral areas respectively in the invasion front, indicating a very good agreement between the two pathologists.

Based on our classification (Table 2), 9\% of the cases were Maspin negative, $44 \%$ presented cytoplasmic predominance, nuclear predominance was revealed in $24 \%$ of the cases, and the other $23 \%$ of CRC presented a mixed nuclear-cytoplasmic Maspin positivity.

In $11 \%$ of cases, Maspin positivity was detected also in the endothelial cells of the mature vessels (Fig. 1), without correlation with other clinico-pathological factors.

Maspin expression in the peritumoral normal or dysplastic mucosa showed a particular aspect. In the normal mucosa and the associated polyps without dysplasia, Maspin expression was observed in the cytoplasm. However, in the high-grade dysplastic polyps, the nuclear pattern was predominant, being lost in the tumor area but re-expressed in the invasion front (Fig. 2).

Independently of the predominant pattern, Maspin expression was not correlated with the patients' age $(p=0.34)$ or with the tumor stage $(p=0.06)$ (Table 3$)$. A slight female predominance $(p=0.003)$ was observed in cases with mixed expression (M/F ratio 2:1) compared to the other groups (5:1 and 7:1) (Table 3).

Most of the cases located on the proximal colon presented mixed Maspin expression (40\%) followed by cytoplasmic predominance $(31 \%)$. The cytoplasmic predominance was more frequent $(56 \%)$ in distal colon carcinomas $(p<0.0001)$ (Table 3).

All cases were adenocarcinomas. Their number, depending on the histological grade is presented in Table 3 . The histological type of tumor was also correlated with Maspin immunoreactivity $(\mathrm{p}<0.0001)$ (Table 3$)$. Most of the poorly differentiated carcino-

Table 3. Clinico-pathological and molecular characteristics of colorectal carcinomas in relation to Maspin expression [n=number of studied cases; G1-3=adenocarcinomas well (G1), moderately (G2) and poorly differentiated (G3); $c$ c. $=$ carcinoma; $M S I=$ microsatellite instability; MSS=microsatellite stable]

\begin{tabular}{|c|c|c|c|c|c|}
\hline \multirow{2}{*}{$\begin{array}{l}\text { Variable } \\
(n=121)\end{array}$} & \multicolumn{4}{|c|}{ Maspin immunoreactivity } & \multirow[b]{2}{*}{$\mathbf{p}$} \\
\hline & cytoplasmic predominance & nuclear predominance & mixed expression & negative & \\
\hline $\begin{array}{l}\text { Age } \\
(\text { mean } \pm S D, \text { years })\end{array}$ & $60.16 \pm 11.05$ & $57.37 \pm 13.42$ & $60.07 \pm 13.11$ & $59.36 \pm 8.32$ & 0.34 \\
\hline Male:female ratio & $7: 1$ & $5: 1$ & $2: 1$ & $5: 1$ & 0.003 \\
\hline $\begin{array}{l}\text { Localization } \\
\text { proximal colon }(n=41) \\
\text { distal colon }(n=24) \\
\text { rectum }(n=56)\end{array}$ & $\begin{array}{l}31 \% \\
56 \% \\
38 \% \\
\end{array}$ & $\begin{array}{l}17 \% \\
33 \% \\
25 \% \\
\end{array}$ & $\begin{array}{l}40 \% \\
10 \% \\
29 \% \\
\end{array}$ & $\begin{array}{c}12 \% \\
1 \% \\
8 \% \\
\end{array}$ & $<0.0001$ \\
\hline $\begin{array}{l}\text { TNM staging } \\
\text { I/II }(\mathrm{n}=43) \\
\text { III/IV }(\mathrm{n}=78)\end{array}$ & $\begin{array}{l}36 \% \\
45 \%\end{array}$ & $\begin{array}{l}27 \% \\
15 \%\end{array}$ & $\begin{array}{l}27 \% \\
35 \%\end{array}$ & $\begin{array}{c}10 \% \\
5 \%\end{array}$ & 0.06 \\
\hline $\begin{array}{l}\text { Histologic type/grade } \\
\text { G1 }(n=20) \\
\text { G2 }(n=65) \\
\text { G3 }(n=27) \\
\text { Mucinous cc. }(n=9)\end{array}$ & $\begin{array}{l}50 \% \\
36 \% \\
50 \% \\
13 \%\end{array}$ & $\begin{array}{l}17 \% \\
31 \% \\
13 \% \\
26 \%\end{array}$ & $\begin{array}{l}28 \% \\
20 \% \\
33 \% \\
48 \%\end{array}$ & $\begin{array}{c}5 \% \\
13 \% \\
14 \% \\
13 \%\end{array}$ & $<0.0001$ \\
\hline $\begin{array}{l}\text { Microsatellite status } \\
\text { MSI }(n=19) \\
\text { MSS }(n=102)\end{array}$ & $\begin{array}{l}30 \% \\
41 \%\end{array}$ & $\begin{array}{l}23 \% \\
26 \%\end{array}$ & $\begin{array}{l}40 \% \\
22 \%\end{array}$ & $\begin{array}{c}7 \% \\
11 \%\end{array}$ & 0.04 \\
\hline $\begin{array}{l}\text { Tumor budding (\%) } \\
\text { present } \\
\text { absent }\end{array}$ & $\begin{array}{l}37 \% \\
32 \%\end{array}$ & $\begin{array}{l}29 \% \\
18 \%\end{array}$ & $\begin{array}{l}29 \% \\
18 \%\end{array}$ & $\begin{array}{c}5 \% \\
32 \%\end{array}$ & $<0.0001$ \\
\hline
\end{tabular}




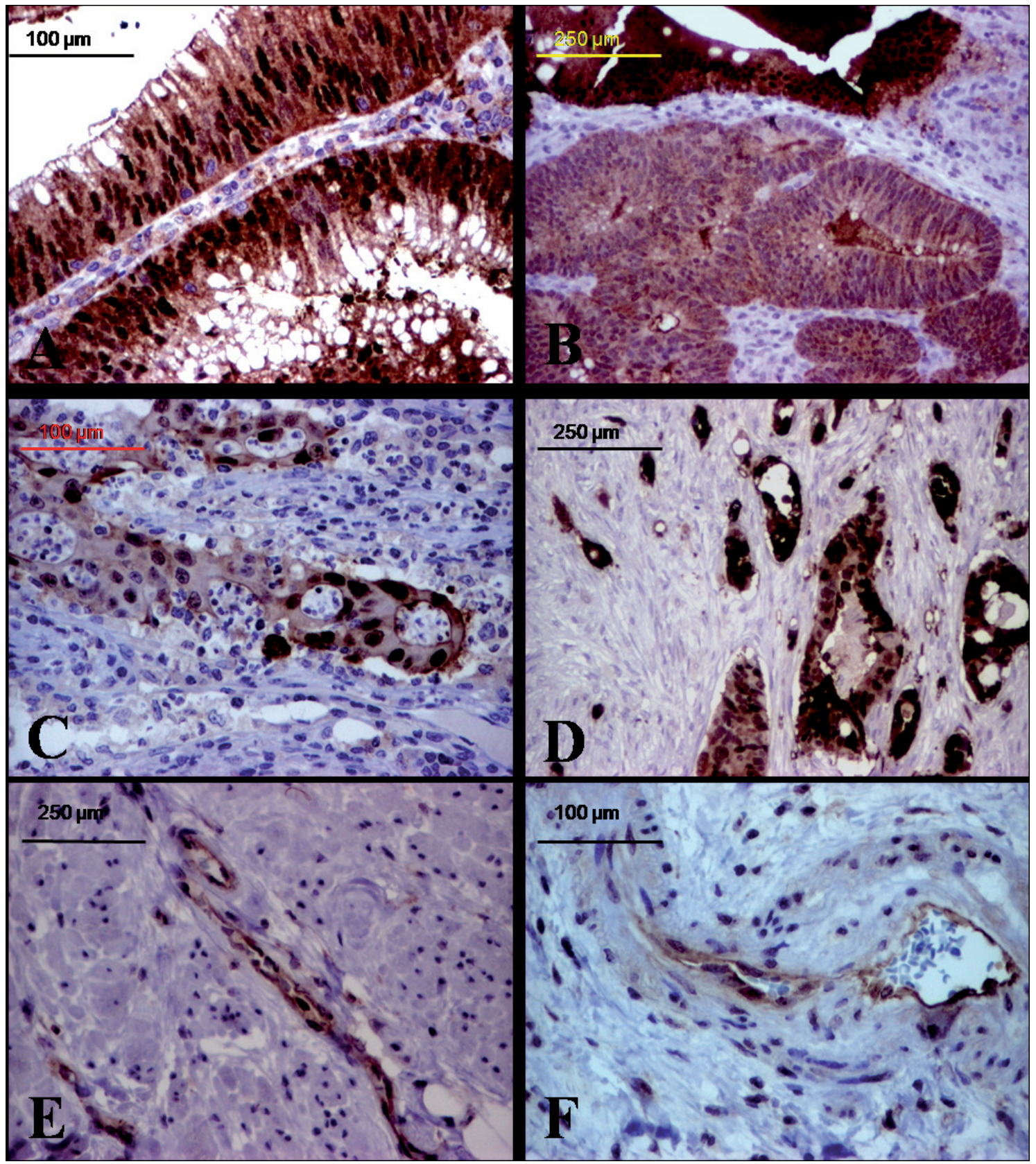

Fig. 2. Maspin expression in colorectal lesions. A-C. The mixed expression in an adenoma with high-grade dysplasia (A, B) with loss of nuclear pattern in carcinoma (B) and nuclear re-expression in the invasion front (C); D. Mixed expression, with increased intensity in the invasion front. E-F. Maspin positivity in the endothelial cells of the mature vessels.

mas (G3) presented cytoplasmic predominance (50\%) or mixed expression (33\%) but mucinous carcinomas had either mixed $(48 \%)$ or nuclear predominance $(26 \%)$.

Maspin expression and the microsatellite status. Most microsatellite instable cases (MSI) presented mixed Maspin expression (40\%) followed by cytoplasm (30\%) and nuclear predominance (23\%). Their location on the proximal colon and the predominance of poorly differentiated and mucinous types confirm the correlation of Maspin immunoreactivity with tumor localization and histological type as previously described in this study.

In the microsatellite stable (MSS) cases, the cytoplasmic predominance was more frequent (41\%), followed by nuclear $(26 \%)$ and mixed positivity (22\%). Maspin was negative in $7 \%$ and $11 \%$ of MSI and MSS cases, respectively (Table 3). All mucinous carcinomas with nuclear predominance, independent of their location, were MSS cases. 


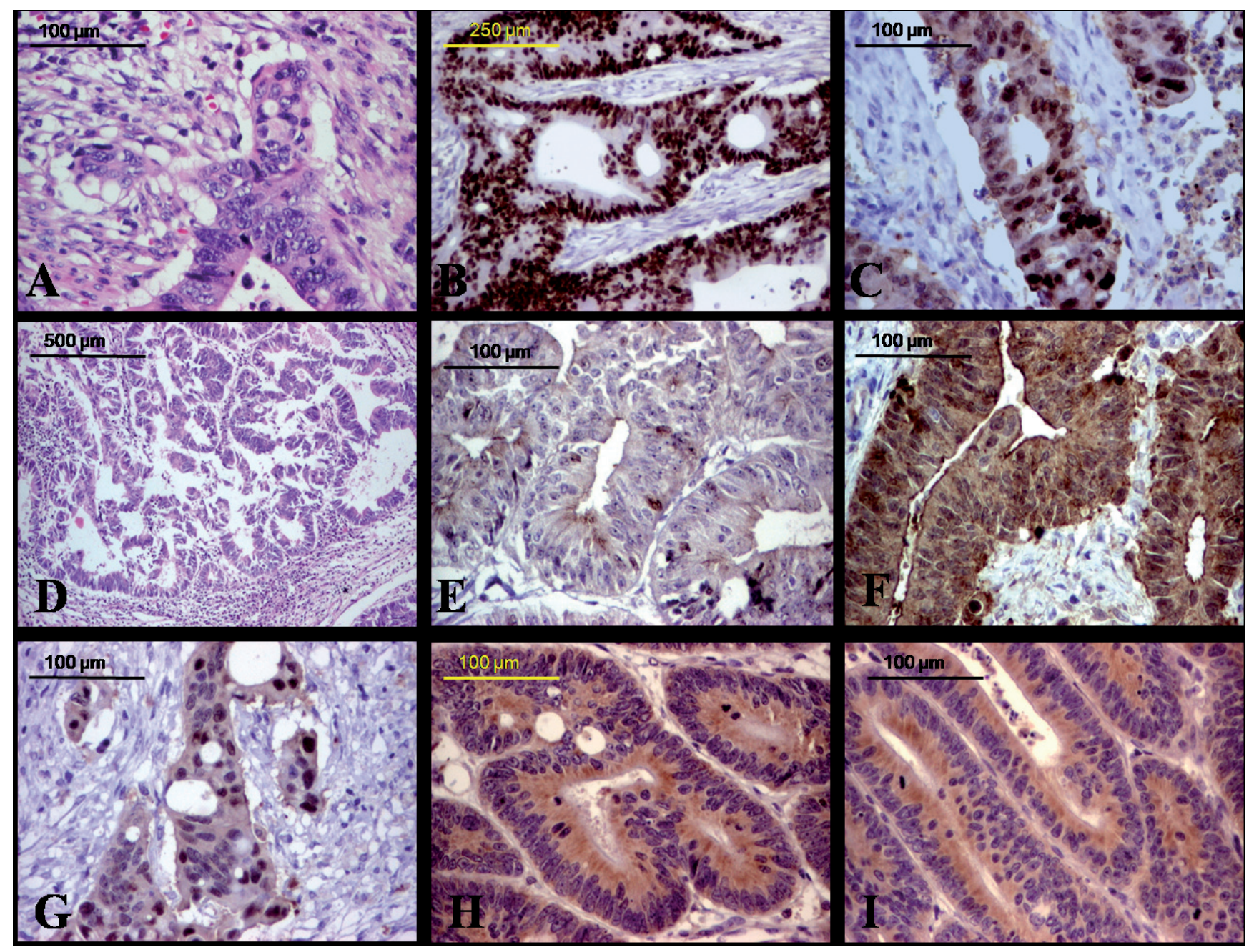

Fig. 3. Correlation of Maspin subcellular localization with other parameters. A-C. In adenocarcinomas with tumor budding (A) p53 positivity (B) and maspin nuclear predominance (C) are associated; D-F. Adenocarcinomas without budding (D) are characterized by p53 negativity (E) and maspin cytoplasmic predominance (F); G-I. Maspin nuclear predominance (G) associates bax- (H) and VEGF-positivity (I)

Maspin expression and tumor budding. For tumor budding quantification, the mean $\kappa$ value was 0.82 , indicating a very good agreement between the two pathologists.

In carcinomas, increasing intensity of both cytoplasmic and nuclear expression was observed in the invasion front, especially in the budding areas (Figs. 1-3). Tumor budding was revealed in 56 of the 121 CRC (46.28\%), out of which $5 \%$ were negative and $95 \%$ were Maspin positive (37\% with cytoplasmic predominance, $29 \%$ nuclear, and $29 \%$ mixed expression). On the other hand, a significantly high percentage of $\mathrm{CRC}$ without budding were Maspin negative (32\%) and 68\% were positive (32\% cytoplasmic predominance, $18 \%$ nuclear and $18 \%$ mixed expression) (Table 3).

Maspin expression and p53 index. In p53-positive CRC, loss of cytoplasmic expression but increased nuclear positivity was more frequent, compared to $p 53$-negative cases $(p<0.0001)$
(Table 4, Fig. 3). P53 positivity was associated with maspin nuclear predominance, this aspect being more frequent in adenocarcinomas with tumor budding (Fig. 3).

Maspin expression and apoptotic markers. Most of Maspin-negative cases were also bax-negative but the mixed and nuclear Maspin expression significantly increased in baxpositive (Fig. 3), compare to bax-negative CRC ( $\mathrm{p}=0.0127$ ). Cytoplasmic Maspin expression was predominant in bcl-2positive, compare to bcl-2-negative cases $(p=0.0013)$ (Table 4).

Some of the endothelial cells marked by Maspin in the mature vessels also presented bax positivity.

Maspin expression and angiogenesis. Most VEGF-positive cases were either Maspin negative or presented Maspin cytoplasmic predominance. Compared to VEGF-negative cases, there was a significant increase of Maspin nuclear 


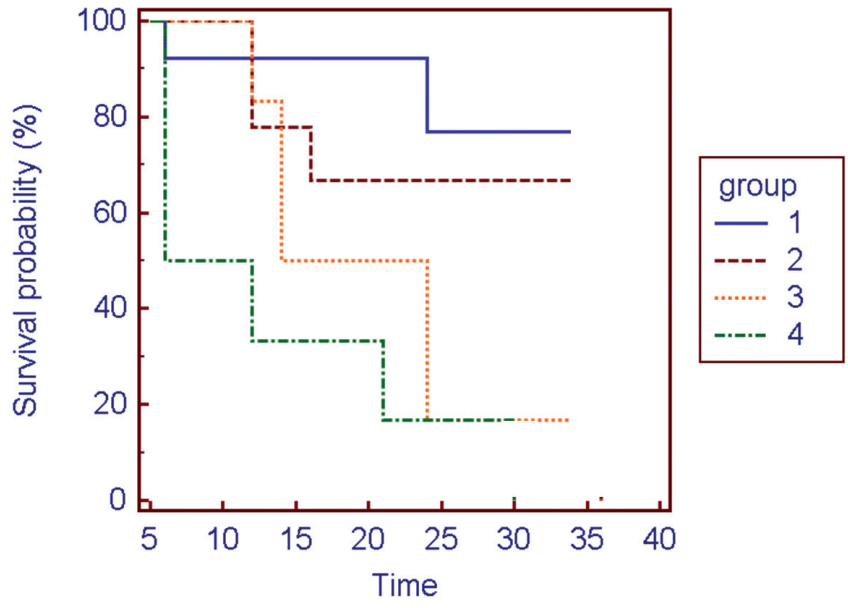

Fig. 4. Kaplan-Meier survival curves by Maspin subcellular localization. Time survival is expressed in months. Group 1: cytoplasmic predominance; group2: mixed expression; group 3: negative and group 4: nuclear predominance

predominance (Table 4, Fig. 3). Cases with mixed Maspin expression presented reverse correlation with VEGF intensity $(p<0.0001)$ and microvessel density (MVD) quantified with CD31 $(p=0.05)$. A slight tendency for higher MVD in Maspin- negative CRC was observed but the difference was at the limit of statistical significance $(p=0.05)$.

Maspin expression and its impact on survival . A 36 months follow-up showed a significant correlation between the survival and Maspin expression $(p=0.002)$, revealed by KaplanMeier curve and Log-Rank testing respectively (Fig. 4).

Prognostic assessment in CRC, based on Maspin expression. Based on previous correlations (Tables 3 and -4) there are four possible prognostic groups of CRC which can be identified. Their characteristics are presented in Table 5. In Group $\mathrm{IV}$, the angiogenesis was more intense compared to the other groups. Most of MSI cases belonged to Group II.

Multivariate analyses. Cox proportional hazards regression indicated that none of the markers or markers combination used in this study (p53, bcl-2, bax, CD31, VEGFA), except Maspin, were correlated to OS (overal survival). Regarding the other parameters also analyzed in univariate analyses, the tumor stage, tumor budding and microstaellite status were independent prognostic factors, strongly correlated with the overal survival $(\mathrm{p}<0.0001)$.

\section{Discussion}

Approximately 536 studies published to date regard Maspin expression, most of them revealing the role of Maspin in inhi-

Table 4. Maspin expression correlated with other immunohistochemical markers and angiogenesis (EA=Endothelial Area)

\begin{tabular}{|c|c|c|c|c|c|}
\hline \multirow{2}{*}{$\begin{array}{l}\text { Biological marker } \\
(\mathrm{n}=121)\end{array}$} & \multicolumn{4}{|c|}{ Maspin immunoreactivity } & \multirow[b]{2}{*}{$\mathbf{p}$} \\
\hline & cytoplasmic predominance & nuclear predominance & mixed expression & negative & \\
\hline \multicolumn{6}{|l|}{ p53 } \\
\hline negative $(n=56)$ & $46 \%$ & $14 \%$ & $36 \%$ & $4 \%$ & $<0.0001$ \\
\hline positive $(n=20)$ & $31 \%$ & $31 \%$ & $19 \%$ & $19 \%$ & \\
\hline \multicolumn{6}{|l|}{ bax } \\
\hline negative $(n=41)$ & $38 \%$ & $22 \%$ & $19 \%$ & $19 \%$ & 0.012 \\
\hline positive $(n=80)$ & $38 \%$ & $29 \%$ & $28 \%$ & $5 \%$ & \\
\hline \multicolumn{6}{|l|}{ bcl-2 } \\
\hline negative $(\mathrm{n}=98)$ & $33 \%$ & $28 \%$ & $27 \%$ & $12 \%$ & 0.001 \\
\hline positive $(n=23)$ & $60 \%$ & $13 \%$ & $20 \%$ & $7 \%$ & \\
\hline \multicolumn{6}{|l|}{ VEGF-A } \\
\hline negative $(\mathrm{n}=55)$ & $45 \%$ & $1 \%$ & $53 \%$ & $1 \%$ & $<0.0001$ \\
\hline positive $(n=66)$ & $46 \%$ & $40 \%$ & $1 \%$ & $13 \%$ & \\
\hline \multicolumn{6}{|l|}{ CD31 } \\
\hline $\mathrm{EA} \leq 1$ & $35 \%$ & $22 \%$ & $35 \%$ & $8 \%$ & 0.05 \\
\hline EA 1-2 & $40 \%$ & $26 \%$ & $23 \%$ & $11 \%$ & \\
\hline $\mathrm{EA}>2$ & $41 \%$ & $24 \%$ & $24 \%$ & $11 \%$ & \\
\hline
\end{tabular}

Table 5. Prognostic assessment in colorectal carcinomas, based on Maspin expression

\begin{tabular}{|c|c|c|c|}
\hline Group number & Prognostic assessment & Maspin immunoreactivity & Other characteristics \\
\hline I & better prognosis & cytoplasmic predominance & p53 negative without budding areas \\
\hline II & intermediary prognosis & mixed expression & p53 negative with budding areas \\
\hline III & intermediary prognosis & negative & p53 positive without budding areas \\
\hline IV & worst prognosis & nuclear predominance & p53 positive with budding areas \\
\hline
\end{tabular}


bition of tumor proliferation and also its antiangiogenic role, but the results are very controversial. A proper assessment of this protein could have a prognostic and predictive impact for daily diagnosis and also for understanding of the tumor behavior. One of the newest studies revealed that Maspin is the first and only endogenous polypeptide inhibitor of histone deacetylase I (HDAC I) which can assure, in case of prostate carcinoma, the tumor redifferentiation, which is a reversal process of epithelial-to-mesenchymal transition [17]. No data were reported about this aspect in CRC.

One of the poorly understood aspects regards the specifical roles of Maspin depending on its subcellular localization and their mechanisms. Some authors mentioned that the Maspin suppressive function is exerted only in the nuclear localization and associates Maspin nuclear positivity with good prognosis in lung cancer [17]. Other researchers reported a down-regulation of maspin during tumor progression and metastasation $[18,19]$, but this aspect is not available in all tumors [20,21].

In colorectal carcinogenesis, Maspin expression increases in the adenoma-carcinoma sequence, being synthesized in the endoplasm reticulum and transferred in the nuclei [12]. On the other hand, cytoplasmic expression tends to decrease during this transformation [22]. One explanation for this cytoplasmic decreasing could be the lost of cell-cell adhesion which is mediated by E-cadherin on the cytoplasmic side $[17,23]$.

The possible role of Maspin in carcinogenesis is also proved by a significantly higher percentage of positivity (92\%) in cases with active idiopathic inflammatory bowel disease (IBD) than in the inactive IBD (43\%) and also by its progressive increased expression in parallel to the grade of dysplasia in these lesions [24].

Our study also revealed decreased cytoplasmic expression in CRC and predominance of the nuclear pattern in both high-grade dysplastic polyps and aggressive CRC. The nuclear pattern can be lost during malignant transformation but it is reexpressed in the invasion front and tumor budding areas.

According to Markl et al. (2010), in Stage I/II of CRC, despite the absence of node metastases, the shift from cytoplasmic to nuclear expression of Maspin is associated with the decrease in overall survival rate [25], indicating that the nuclear expression of Maspin in node-negative CRC can help the pathologist to identify those $20 \%$ of cases from Stage I or II with fatal clinical outcome. In Stage III of CRC, with lymph node metastases, increased nuclear Maspin expression also seems to indicate shorter survival and local aggressiveness and correlates with the tumor grade, but not with p53 expression [7].

Our results sustain the association of nuclear predominance with tumor aggressivity, independently from the tumor stage. At the same time, the cytoplasmic predominance and mixed expression could indicate a more favorable outcome.

The percentage of nuclear-positive cases is higher in poorly differentiated MSI carcinomas than in the MSS group, without significant difference of cytoplasmic expression depending on the microsatellite status [7]. Other authors reported that both cytoplasmic and nuclear Maspin expression are higher in poorly differentiated right-sided tumors [26]. Our study confirmed these findings but added new details. The cytoplasmic expression was more frequent in MSS cases located on the distal colon but mixed expression was more characteristic for MSI cases, which were poorly differentiated or of the mucinous type, were right-sided and were associated with lower angiogenesis.

A persistent aspect observed in our cases, in line with data published in the literature, was the increase of both cytoplasmic and nuclear positivity rate in the invasion front [7] and tumor budding areas [11], which can suggest the correlation of Maspin activity with tumor aggressivity. Maspin is mostly expressed in cases with high-grade tumor budding [11], similar to our study.

It was suggested that Maspin up-regulation could have a p53-dependent regulatory pathway [22,27], however, not all authors reported the same aspect [11]. P53 positivity is higher in Maspin-negative cases compared to the cytoplasm-positive ones [22,27], sustaining our results.

The tendency for higher MVD in Maspin-negative CRC $[12,22]$ is in line with our results, although the difference is at the limit of statistical significance $(p=0.05)$. Mixed Maspin positivity was reversely correlated with MVD and VEGF expression but nuclear predominance presented a direct correlation with VEGF expression.

The correlation between Maspin expression and survival is also controversial. Maspin positivity indicated either an increased or a decreased overall survival rate [27]. No correlation was also reported, probably due to different genetic backgrounds $[12,26]$. Similar to our study, Dietmaier et al. proved that nuclear Maspin expression is an adverse prognostic factor for overall survival rate [7] and Boltze [27] described longer survival rate in cytoplasm-expressing CRC.

In conclusion, one of the novelties of our study was the proposal of a new and complex system for Maspin assessment, which includes both cytoplasmic and nuclear scorring. This system proved that Maspin is indeed a protein with complex functions, its role depending on the Maspin subcellular localization. Based on Maspin expression in CRC, four groups of patients can be identified, with possible prognostic impact. Nuclear positivity associates high agressivity and a shorter survival, but the cytoplasmic ones reveals a better prognosis. The newest aspect of our data regards the mixed expression (cytoplasmic and nuclear) which associates a better survival than in case of nuclear predominance or lack of Maspin immunostain.

Further studies are necessary to elucidate the molecular mechanisms of Maspin activity and the real significance of Maspin mixed expression, as first reported in our study. To best judge expression correlations of Maspin in colorectal cancer, the double labeling for maspin and other markers as p53, bcl-2 and bax should be performed. 
If our observations are proved to be correct, in a high number of patients, this new scorring system could be used for risk stratification of patients with non-metastatic colorectal carcinomas which could benefit by an adjuvant therapy, with a Maspin-targeted drug.

In this paper, our intention was to sensitize the researchers about the necessity of a reliable scorring system for Maspin expression in CRC, mandatory to be improved, in order to elucidate the published controversial results.

Acknowledgements: This work was partially supported by the National Fellowship L'Oreal - UNESCO "For Women in Science" and the contract POSDRU/89/1.5/S/60782. The English-language manuscript was polished by SPI Global Professional Editing Service.

\section{References}

[1] RAVENHILL L, WAGSTAFF L, EDWARDS DR, ELLIS V, BASS R G-helix of Maspin Mediates Effects on Cell Migration and Adhesions. J Biol Chem 2010; 285: 36285-36292. http://dx.doi.org/10.1074/jbc.M110.177253

[2] ZOU Z, ANISOWICZ A, HENDRIX MJC, THOR A, NEVEU $M$ et al. Maspin: A Serpin with tumor suppressing activity in human mammary epithelial cells. Science 1994; 263: 526-529. http://dx.doi.org/10.1126/science.8290962

[3] SHAO ZM, NGUYEN M, ALPAUGH ML, O`CONNELL JT, BARSKY SH The human myoepithelial cell exerts antiproliferative effects on breast carcinoma cells characterized by 21 waf1/cip1 induction, G2/M arrest and apoptosis. Exp Cell Res 1998; 241: 394-403. http://dx.doi.org/10.1006/ excr.1998.4066

[4] QIN L, ZHANG M Maspin regulates endothelial cell adhesion and migration through an integrin signaling pathway. J Biol Chem 2010; 285: 32360-32369. http://dx.doi.org/10.1074/jbc. M110.131045

[5] LI Z, SHI HY, ZHANG M Targeted expression of maspin in tumor vasculatures induces endothelial cell apoptosis. Oncogene 2005; 24: 2008-2019. http://dx.doi.org/10.1038/ sj.onc. 1208449

[6] IMPAGNATIELLO MA, BIANCHI E, DI STEFANO R, PARDI R, MOSCA F A novel approach to identification of genes involved in neo-angiogenesis: implication for graft revascularization. Transplant Proc 1997; 29: 1110. http://dx.doi. org/10.1016/S0041-1345(96)00450-2

[7] DIETMAIER W, BETTSTETTER M, WILD PJ, WOENCKHAUS M, RUMMELE $P$ et al. Nuclear Maspin expression is associated with response to adjuvant 5 -fluorouracil based chemotherapy in patients with stage III colon cancer. Int J Cancer 2005; 118: 2247-2254. http://dx.doi.org/10.1002/ ijc. 21620

[8] WOENCKHAUS M, BUBENDORF L, DALQUEN P, FOERSTER J, BLASZYK $\mathrm{H}$ et al. Nuclear and cytoplasmic Maspin expression in primary non-small cell lung cancer. J Clin Pathol 2007; 60: 483-486. http://dx.doi.org/10.1136/ jcp.2005.033407
[9] UMEKITA Y, OHI Y, SAGARA Y, YOSHIDA H. Expression of maspin predicts poor prognosis in breast-cancer patients. Int J Cancer 2002; 100: 452-455. http://dx.doi.org/10.1002/ ijc. 10500

[10] REIS-FILHO JS, TORIO B, ALBERGARIA A, SCHMITT FC Maspin expression in normal skin and usual cutaneous carcinomas. Virchows Arch 2002; 441: 551-558. http://dx.doi. org/10.1007/s00428-002-0710-1

[11] UMEKITA Y, SOUDA M, YOSHIDA H Expression of maspin in colorectal cancer. In vivo 2006; 20: 797-800.

[12] ZHENG H, TSUNEYAMA K, CHENG C, HIROYUKI T, ZHENGGUO $\mathrm{C}$ et al. Maspin expression was involved in colorectal adenoma-adenocarcinoma sequence and liver metastasis of tumors. Anticancer Res 2007; 27: 259-266.

[13] UENO H, MURPHY J, JASS JR, MOCHIZUKI H, TALBOT IC. Tumor, budding' as an index to estimate the potential of agressiveness in rectal cancer. Histopathology 2002; 40: 127-132. http://dx.doi.org/10.1046/j.1365-2559.2002.01324. $\underline{\mathrm{x}}$

[14] JANAVICIUS R, MATIUKAITE D, JAKUBAUSKAS A, GRISKEVICIUS L Microsatellite instability detection by High-Resolution Melting analysis. Clin Chem 2010; 56: 1750 1757. http://dx.doi.org/10.1373/clinchem.2010.150680

[15] DIETMAIER W, WALLINGER S, BOCKER T, KULLMANN F, FISHEL R, RUSCHOFF J Diagnostic microsatellite instability: definition and correlation with mismatch repair protein expression. Cancer Res 1997; 57: 4749-4756.

[16] COHEN J Weighted kappa: nominal scale agreement with provision for scale disagreement or partial credit. Psychol Bull 1968; 70: 213-230. http://dx.doi.org/10.1037/ $\underline{\mathrm{h} 0026256}$

[17] BERNARDO MM, MENG Y, LOCKETT J, DYSON G, DOMGOWSKY A et al. Maspin reprograms the gene expression profile of prostate carcinoma cells for differentiation. Genes Cancer 2011; 2: 1009-1022. http://dx.doi.org/10.1177/ 1947601912440170

[18] BAILEY CM, KHALKHALI-ELLIS Z, SEFTOR EA, HENDRIX MJ. Biological functions of maspin. J Cell Physiol 2006; 209: 617-624. http://dx.doi.org/10.1002/jcp.20782

[19] LOCKETT J, YIN S, LI X, MENG Y, SHENG S Tumor suppressive maspin and epithelial homeostasis. J Cell Biochem 2006; 97: 651-660. http://dx.doi.org/10.1002/jcb.20721

[20] SOOD AK, FLETCHER MS, GRUMAN LM, COFFIN JE, JABBARI $S$ et al. The paradoxical expression of maspin in ovarian carcinoma. Clin Cancer Res 2002; 8: 2924-2932.

[21] YU M, ZHENG H, TSUNEYAMA K, TAKAHASHI H, NOMOTO K et al. Paradoxical expression of maspin in gastric carcinomas: correlation with carcinogenesis and progression. Hum Pathol 2007; 238: 1248-1255. http://dx.doi.org/10.1016/ j.humpath.2006.11.025

[22] SONG SY, LEE SK, KIM DH, SON HE, KIM HJ, et al. Expression of maspin in colon cancers. Its relationship with p53 expression and microvessel density. Digest Dis Sci 2002; 47: 1831-1835. http://dx.doi.org/10.1023/A:1016409031562

[23] YILMAZ M, CHRISTOFORI G Mechanism of motility in metastasizing cells. Mol Cancer Res 2010; 8: 629-642. http:// dx.doi.org/10.1158/1541-7786.MCR-10-0139 
[24] CAO D, WILENTZ RE, ABBRUZZESE JL, HO L, MAITRA A. Aberrant expression of Maspin in idiopathic inflammatory bowel disease is associated with disease activity and neoplastic transformation. Int J Gastrointest Cancer 2005; 36: 39-46. http://dx.doi.org/10.1385/IJGC:36:1:039

[25] MARKL B, AMHOLDT HM, JAHNIG H, SCHENKIRSCH G, HERMANN RA et al. Shift to cytoplasmic to nuclear maspin expression correlates with shorter overall survival in node-negative colorectal cancer. Hum Pathol 2010; 41: 10241033. http://dx.doi.org/10.1016/j.humpath.2009.10.021
[26] FUNG CL, CHAN C, JANKOVA L, DENT OF, ROBERTSON G et al. Clinicopathological correlates and prognostic significance of maspin expression in 450 patients after potentially curative resection of node-positive colonic cancer. Histopathology 2010; 56:319-330. http://dx.doi.org/10.1111/ j.1365-2559.2010.03479.x

[27] BOLTZE C. Loss of maspin is a helpful prognosticator in colorectal cancer: a tissue microarray analysis. Pathol Res Pract 2005; 200: 783-790. http://dx.doi.org/10.1016/ j.prp.2004.10.004 